Article

\title{
The Enhancement of Mg Corrosion Resistance by Alloying Mn and Laser-Melting
}

\author{
Youwen Yang ${ }^{1,+}{ }^{\dagger}$ Ping $\mathrm{Wu}^{2,+}{ }^{\text {, Qiyuan Wang }}{ }^{3}$, Hong Wu ${ }^{4}$, Yong Liu ${ }^{4}$, Youwen Deng ${ }^{3}$, \\ Yuanzhuo Zhou ${ }^{1}$ and Cijun Shuai ${ }^{1,4, *}$ \\ 1 State Key Laboratory of High Performance Complex Manufacturing, Central South University, \\ Changsha 410083, China; yangyouwen@csu.edu.cn (Y.Y.); zyz420357155@csu.edu.cn (Y.Z.) \\ 2 College of Chemistry, Xiangtan University, Xiangtan 411105, China; pingwu@xtu.edu.cn \\ 3 Department of Emergency Medicine, 2nd Xiangya Hospital of Central South University, \\ Changsha 410083, China; idletwo@gmail.com (Q.W.); dengjunjiejj@csu.edu.cn (Y.D.) \\ 4 State Key Laboratory for Powder Metallurgy, Central South University, Changsha 410083, China; \\ hwucsu@csu.edu.cn (H.W.); yonliu@csu.edu.cn (Y.L.) \\ * Correspondence: shuai@csu.edu.cn; Tel.: +86-731-8480-5412; Fax: +86-731-8887-9044 \\ + These authors contributed equally to this work.
}

Academic Editor: Regine Willumeit-Römer

Received: 21 January 2016; Accepted: 17 March 2016; Published: 23 March 2016

\begin{abstract}
Mg}$ has been considered a promising biomaterial for bone implants. However, the poor corrosion resistance has become its main undesirable property. In this study, both alloying $\mathrm{Mn}$ and laser-melting were applied to enhance the $\mathrm{Mg}$ corrosion resistance. The corrosion resistance, mechanical properties, and microstructure of rapid laser-melted $\mathrm{Mg}-x \mathrm{Mn}(x=0-3 \mathrm{wt} \%)$ alloys were investigated. The alloys were composed of dendrite grains, and the grains size decreased with increasing Mn. Moreover, Mn could dissolve and induce the crystal lattice distortion of the $\mathrm{Mg}$ matrix during the solidification process. Mn ranging from 0-2 wt \% dissolved completely due to rapid laser solidification. As Mn contents further increased up to $3 \mathrm{wt} \%$, a small amount of $\mathrm{Mn}$ was left undissolved. The compressive strength of Mg-Mn alloys increased first (up to $2 \mathrm{wt} \%$ ) and then decreased with increasing Mn, while the hardness increased continuously. The refinement of grains and the increase in corrosion potential both made contributions to the enhancement of $\mathrm{Mg}$ corrosion resistance.
\end{abstract}

Keywords: corrosion resistance; Mg-Mn alloy; laser-melting; microstructure; mechanical properties

\section{Introduction}

Recently, Mg has attracted widespread attention as new biodegradable material for bone implants due to its inherent degradability, proper mechanical properties, and good biocompatibility [1-3]. However, the corrosion rate of $\mathrm{Mg}$ in body fluid is too fast to allow the $\mathrm{Mg}$-based implants to maintain its mechanical strength during the recovery of injured bone (at least three months) [4,5]. Moreover, the fast corrosion of $\mathrm{Mg}$ results in the release of a large amount of hydrogen gas in body fluid, which is detrimental for the host tissue [6].

Alloying is an effective method to enhance the $\mathrm{Mg}$ corrosion resistance. Biodegradable $\mathrm{Mg}-\mathrm{Ca}$ alloys have been developed and have demonstrated an improved corrosion behavior both in simulated body fluid (SBF) and Hank's solutions [7,8]. The Mg-Sr alloy system was designed, and the results indicated that the addition of $2 \mathrm{wt} \% \mathrm{Sr}$ improved the $\mathrm{Mg}$ corrosion resistance [9]. Other Mg alloys, such as AZ31, AZ91, WE43, and LAE442, have also been reported to have improved Mg corrosion resistance [10,11].

Rapid solidification is also an effective method to enhance the $\mathrm{Mg}$ corrosion resistance. Laser-melting is a typical rapid solidification technology involving a cooling rate above $10^{5} \mathrm{~K} / \mathrm{s}[12,13]$. 
The high cooling rate will prevent the growth of grains for finer crystalline structure, which has a beneficial effect on enhancing the $\mathrm{Mg}$ corrosion resistance [14,15]. Meanwhile, rapid laser-melting is able to homogenize the compositional distribution, thus limiting the local cell action caused by the accumulation of cathodic phases [16]. Furthermore, rapid laser-melting could increase the solid solubility of alloying elements, such as $\mathrm{Mn}, \mathrm{Al}$, and $\mathrm{Cr}$, promoting the formation of more protective and self-healing films [16]. Mn is an essential element in human bone, and its average daily intake of an adult is about $5-10 \mathrm{mg}$ [17]. Furthermore, the in vivo test revealed that it promoted cell proliferation and bone regeneration [18]. Furthermore, Gu etc. [19] have studied the mechanical properties, corrosion properties, and in vitro biocompatibilities of as-cast $\mathrm{Mg}-1 \mathrm{Mn}$ (wt \%) alloys, which suggests that the addition of alloying element $\mathrm{Mn}$ could improve the strength and corrosion resistance of $\mathrm{Mg}$.

In this paper, both alloying Mn and rapid laser-melting were applied to enhance the $\mathrm{Mg}$ corrosion resistance. Basing on the $\mathrm{Mg}-\mathrm{Mn}$ binary phase diagram, the solubility of $\mathrm{Mn}$ in $\mathrm{Mg}$ at room temperature is below $1 \mathrm{wt} \%$, and increases to $\sim 2 \mathrm{wt} \%$ at $750{ }^{\circ} \mathrm{C}$ [20].Thus, we designed a series of Mg-Mn alloys containing Mn from 0-3 wt \%. The corrosion resistance, mechanical properties, and microstructure of rapid laser-melted $\mathrm{Mg}-\mathrm{Mn}$ alloys were investigated.

\section{Results and Discussion}

\subsection{Microstructure Characteristics}

The Mg- $x \mathrm{Mn}$ alloys consisted of dendrite grains whose sizes decreased with increasing Mn (Figure 1). Pure Mg presented relatively large dendrite ( 20 $\mathrm{m}$ ) (Figure 1a). As Mn increased to $2 \mathrm{wt} \%$, the grains reduced to $\sim 15 \mu \mathrm{m}$ (Figure 1c). With Mn further increasing up to 3 wt $\%$, the grains were further refined $(\sim 10 \mu \mathrm{m})$ (Figure 1d). Obviously, rapid laser-melted $\mathrm{Mg}$ alloys had finer grains compared to powder metallurgy processed $\mathrm{Mg}$ alloys with a typical grain size of $50 \mu \mathrm{m}[21,22]$ and casted Mg alloys with larger grain sizes [7].
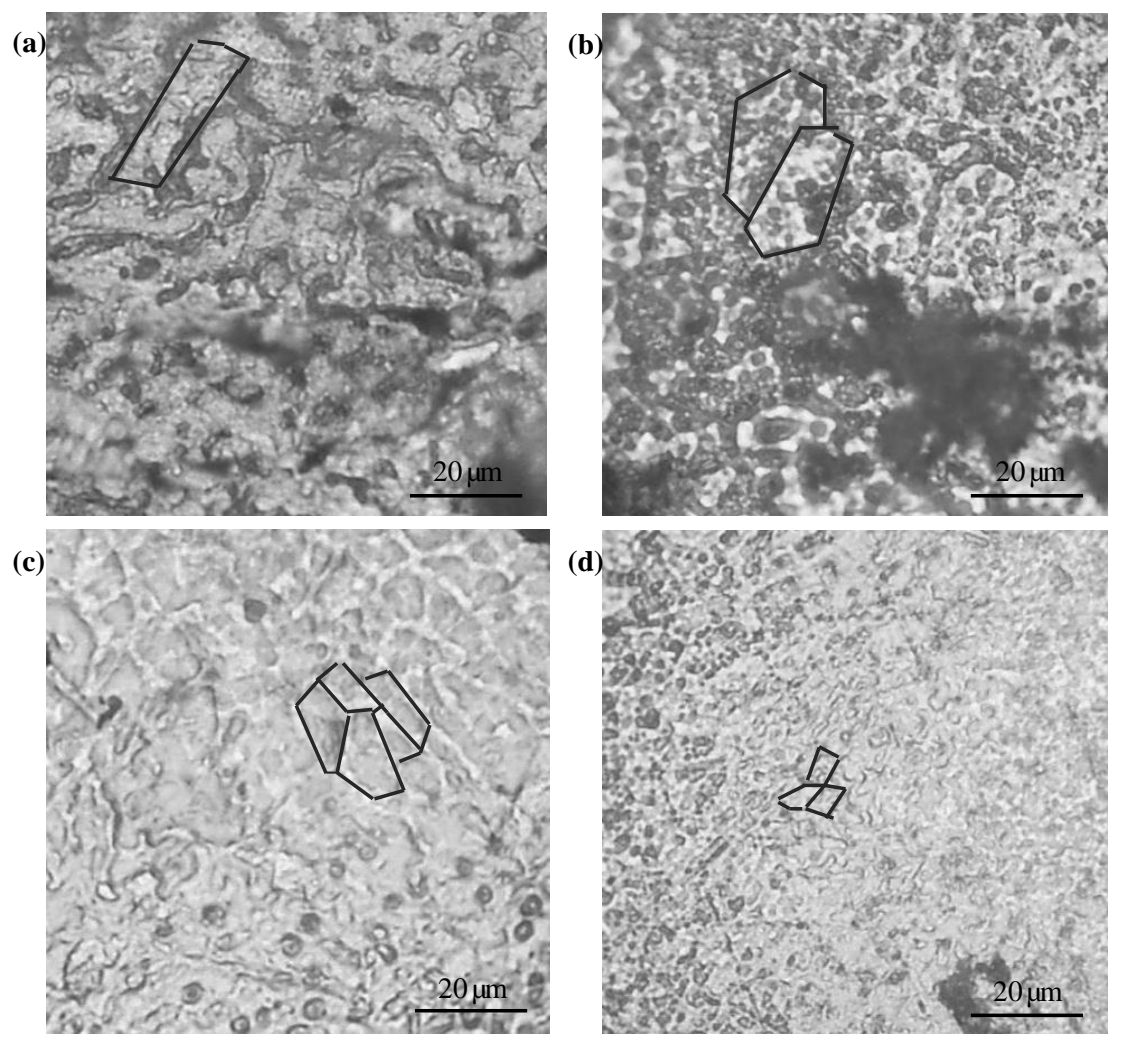

Figure 1. Crystalline structures of laser-melted Mg- $x \mathrm{Mn}$ alloys: (a) pure $\mathrm{Mg}$; (b) $\mathrm{Mg}-1 \mathrm{Mn}$ alloy; (c) Mg-2Mn alloy; (d) Mg-3Mn alloy. 
The phase composition of Mg- $x \mathrm{Mn}$ alloys was tested by X-ray diffractometer (XRD) within a wide $2 \theta$ range $\left(30^{\circ}-80^{\circ}\right)$ (Figure $2 \mathrm{a}$ ). The results showed that only diffraction peaks of the $\mathrm{Mg}$ phase were detected in the $\mathrm{Mg}-1 \mathrm{Mn}$ and $\mathrm{Mg}-2 \mathrm{Mn}$ alloys, while the diffraction peaks of both $\mathrm{Mg}$ and $\mathrm{Mn}$ phases were detected in the Mg-3Mn alloy. It indicated that Mn ranging from 0 to 2 wt \% completely dissolved in the $\mathrm{Mg}$ matrix due to the rapid solidification and formed supersaturated solid solutions. However, 3 wt \% Mn exceeded the solubility limit $\sim 2 \mathrm{wt} \%$ at $750{ }^{\circ} \mathrm{C}$ (melten pool temperature); thus, a small amount of $\mathrm{Mn}$ phase was left undissolved in the $\mathrm{Mg}$ matrix after the rapid solidification.
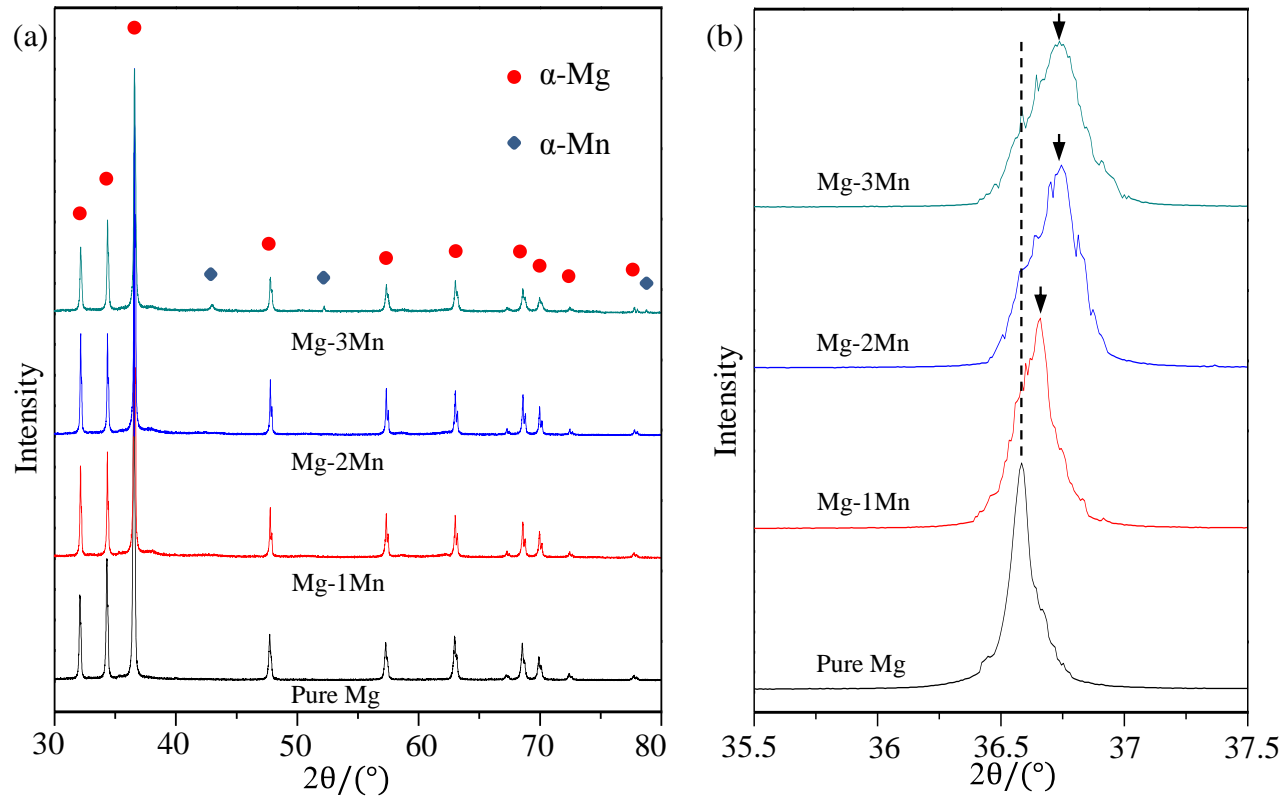

Figure 2. (a) X-ray diffractometer (XRD) spectrum of rapid laser-melted Mg-Mn alloy obtained over $30^{\circ}-80^{\circ}$; (b) XRD spectra in the vicinity of the standard diffraction peak of $\mathrm{Mg} 2 \theta=36.53^{\circ}$.

The XRD characterization within a small $2 \theta$ range $\left(35.5^{\circ}-37.5^{\circ}\right)$ (Figure $\left.2 b\right)$ revealed that the location of the diffraction peak for $\mathrm{Mg}$ apparently changed with increasing $\mathrm{Mn}$. The standard diffraction peak of $\mathrm{Mg}\left(2 \theta=36.53^{\circ}\right)$ was taken for comparison (Table 1). The $2 \theta$ location of diffraction peak detected in rapid laser-melted pure $\mathrm{Mg}$ was the same as that of the standard $\alpha$-phase $\mathrm{Mg}$. For $\mathrm{Mg}-1 \mathrm{Mn}$, the $2 \theta$ location of the diffraction peak of $\mathrm{Mg}$ shifted to a higher $2 \theta$ location. Meanwhile, more significant shifts of $2 \theta$ locations were detected in the $\mathrm{Mg}-2 \mathrm{Mn}$ and $\mathrm{Mg}-3 \mathrm{Mn}$ alloys. According to Bragg's law [23]:

$$
2 d \cdot \sin \theta=n \lambda(n=1,2,3 \cdots)
$$

Table 1. The location, lattice spacing, and intensity variation of identified diffraction peak of $\mathrm{Mg}$ phase.

\begin{tabular}{cccccc}
\hline Sample & Standard & Pure Mg & Mg-1Mn & Mg-2Mn & Mg-3Mn \\
\hline 20 location $\left(^{\circ}\right)$ & 36.53 & 36.53 & 36.59 & 36.71 & 36.72 \\
Lattice spacing $(\AA)$ & 2.45772 & 2.45772 & 2.45382 & 2.44608 & 2.44543 \\
Intensity (CPS) & - & 5709 & 5309 & 5016 & 4220 \\
\hline
\end{tabular}

The shift of $2 \theta$ indicated a change of $d$, namely, the lattice plane distance, which was believed to be induced by the solid solution of $\mathrm{Mn}$. When $\mathrm{Mn}$ dissolved in the $\mathrm{Mg}$ matrix, $\mathrm{Mn}$ atoms replaced the $\mathrm{Mg}$ atoms in the $\mathrm{Mg}$ lattice, which had an arrangement of a hexagonal close-packed structure. However, the atomic radius of $\mathrm{Mn}$ is larger than that of $\mathrm{Mg}$; thus, the replacement of $\mathrm{Mn}$ atoms may lead to a crowding on the spatial location of the surrounding $\mathrm{Mg}$ atoms. As a consequence, the lattice spacing 
decreased gradually as $\mathrm{Mn}$ dissolved (Table 1). Moreover, the diffraction peaks of $\mathrm{Mg}$ in the $\mathrm{Mg}-3 \mathrm{Mn}$ alloy became considerably broad (Figure 2b), and the intensity decreased significantly (Table 1), which implied the formation of finer grains.

Back scattered electron (BSE) imaging combined with energy dispersive spectroscopy (EDS) were used to further illustrate the compositional distribution of Mg- $x \mathrm{Mn}$ alloys (Figure 3). The BSE image (Figure 3a) with uniform gray level revealed that there was only one phase in the Mg-2Mn alloy. Meanwhile, the corresponding EDS point results (Figure 3d) revealed that the ratio of Mn in the Mg-2Mn matrix was $1.96 \mathrm{wt} \%$, which was very close to that in the original powder ( $2 \mathrm{wt} \%$ ). Additionally, the corresponding EDS map (Figure 3b) suggested that Mn was homogeneously distributed in the Mg-2Mn alloy. Additionally, there were a few bright grains, as shown in Figure 3c, unorderly distributed in the Mg-3Mn alloy. The EDS point analysis indicated that the bright grains were undissolved Mn particles (Figure 3e). The appearance of distinct gray level (intensity of BSE signal) between the Mg matrix (dark) and the Mn grains (bright) was due to the fact that Mn has a higher atomic number.

(a)
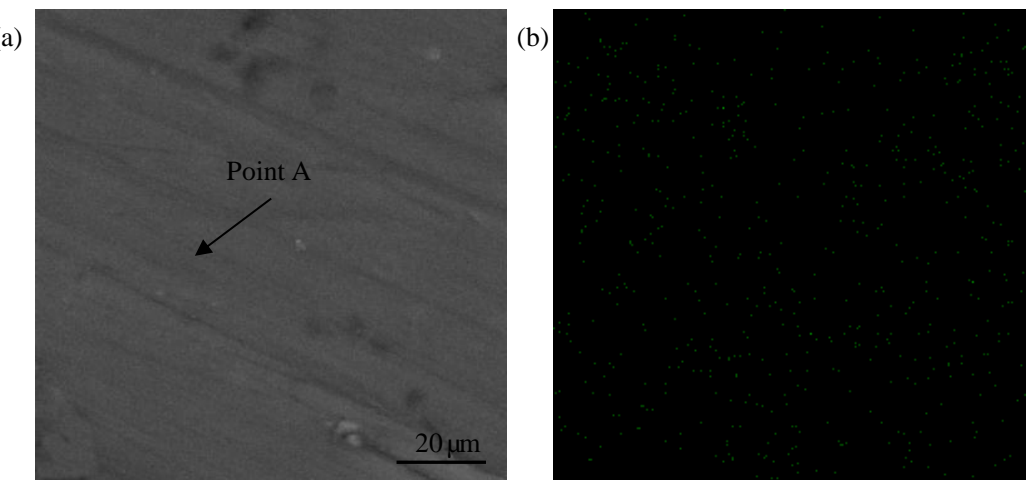

(c)
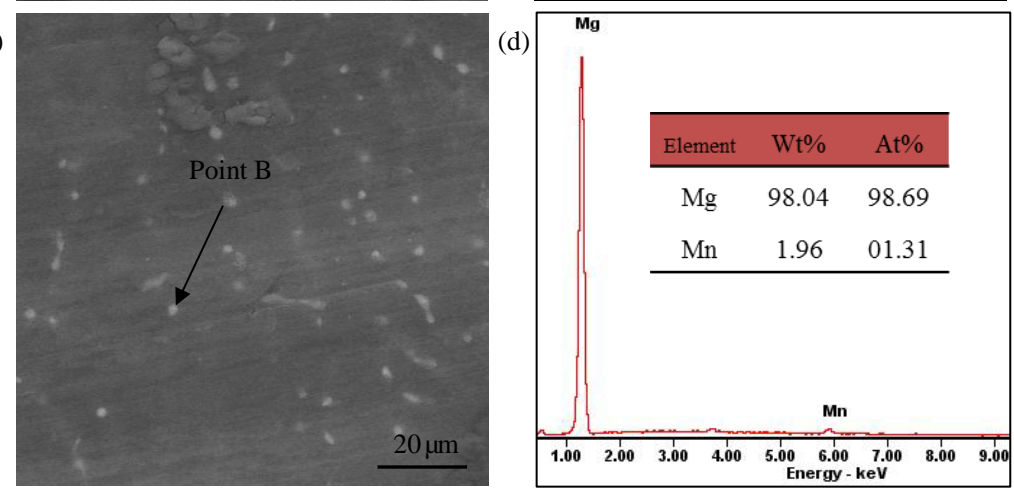

(e)

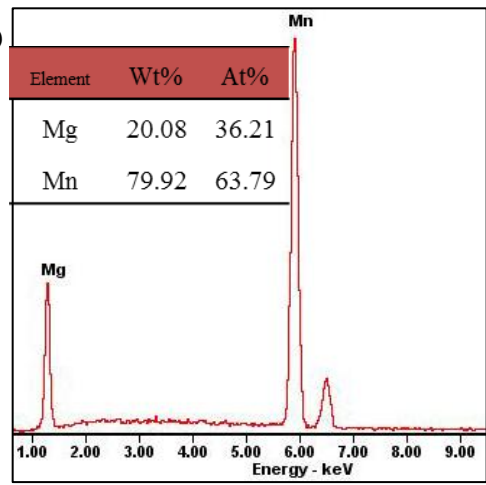

Figure 3. (a) BSE image of Mg-2Mn alloy; (b) EDS map of Mn element in Mg-2Mn alloy; (c) BSE image of Mg-3Mn alloy; (d) Corresponding point EDS analysis marked by arrow A in Figure 3a; (e) Corresponding point EDS analysis of bright grain marked by arrow B in Figure 3c. 


\subsection{Mechanical Properties}

The mechanical properties of rapid laser-melted $\mathrm{Mg}-x \mathrm{Mn}$ alloys were tested (Figure 4). It can be seen that the compressive strength firstly increased from 47.1 MPa for pure $\mathrm{Mg}$ to $64.2 \mathrm{MPa}$ for the $\mathrm{Mg}-2 \mathrm{Mn}$ alloy, and was followed by a decrease to $60.4 \mathrm{MPa}$ with increasing Mn up to $3 \mathrm{wt} \%$. The improved compression strength was partly attributed to the fine grain strengthening effect. The plastic deformation could be dispersed into more grains with the size of grains decreasing, leading to an improved ability to withstand the external force. On the other hand, the solid solution of Mn caused a crystal lattice distortion in the Mg matrix, which was expected to retard dislocation sliding during the deformation and further improved the compression strength. However, the undissolved Mn phase resulted in a weak interface between adjacent $\mathrm{Mg}$ and $\mathrm{Mn}$ grains where the cracks were easy to expand, which impaired the compressive strength of the Mg-3Mn alloy.

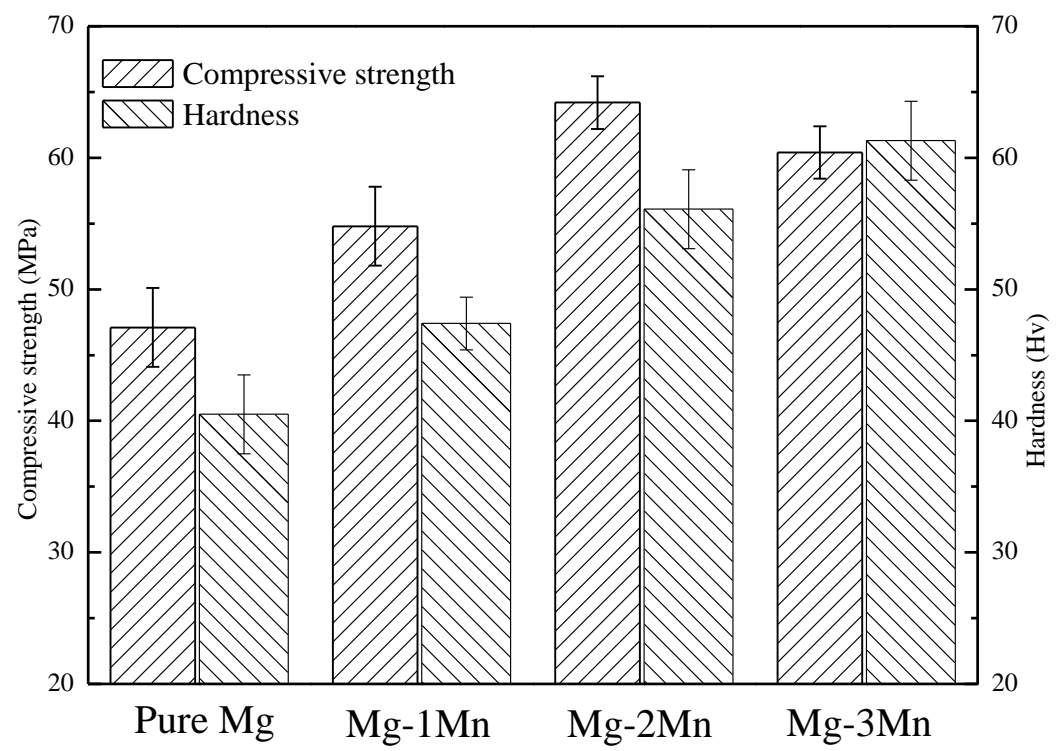

Figure 4. The compressive strength and hardness of Mg-Mn alloys.

In addition, as $\mathrm{Mn}$ increased from 0 to $3 \mathrm{wt} \%$, the hardness increased from $40.5 \mathrm{Hv}$ for pure $\mathrm{Mg}$ to $56.1 \mathrm{Hv}$ for the $\mathrm{Mg}-2 \mathrm{Mn}$ alloy and $61.3 \mathrm{Hv}$ for the $\mathrm{Mg}-3 \mathrm{Mn}$ alloy. The improved hardness of the alloys was due to the solid solution strengthening and fine grain strengthening. With respect to the role of grain refinement, $\mathrm{Ng}$ [24] revealed that laser-melted pure $\mathrm{Mg}$ (grain sizes of $\sim 4 \mu \mathrm{m}$ ) obtained by specific process parameters exhibited a hardness of $\sim 63 \mathrm{Hv}$, which was higher than that of the $\mathrm{Mg}-2 \mathrm{Mn}$ alloy. It was believed that grain refinement had a more dominant effect on improving the mechanical properties of $\mathrm{Mg}$ alloys. Moreover, the undissolved $\mathrm{Mn}$ phase in the Mg-3Mn alloy was also responsible for the improved hardness due to the higher hardness of $\mathrm{Mn}$ than that of $\mathrm{Mg}$.

\subsection{Corrosion Resistance}

The surface morphologies of the Mg- $x \mathrm{Mn}$ alloy after soaking in SBF for $48 \mathrm{~h}$ are shown in Figure 5. The pure Mg exhibited a cracked surface, which was covered with a large amount of corrosion product (Figure 5a). The appearance of cracks is believed to be caused by the dehydration of the corrosion product layer after drying in warm air and under the vacuum of the SEM chamber [25]. For the Mg-1Mn alloy, local areas presented relatively shallow cracks (area B in Figure 5b), while some positions (typically area A in Figure $5 \mathrm{~b}$ ) were still covered with integrated protective film. In contrast, the surface of the $\mathrm{Mg}-2 \mathrm{Mn}$ alloy maintained the integrity of the corrosion film, and the scratches caused by the pretreatment of the sample could be easily observed (Figure $5 \mathrm{c}$ ), which implied that the corrosion on the surface of the Mg-2Mn alloy was relatively slight. As for the Mg-3Mn alloy, some 
positions on the surface were severely destroyed, and deep corrosion pits, as shown in Figure $5 \mathrm{~d}$, were left on the surface.

(a)

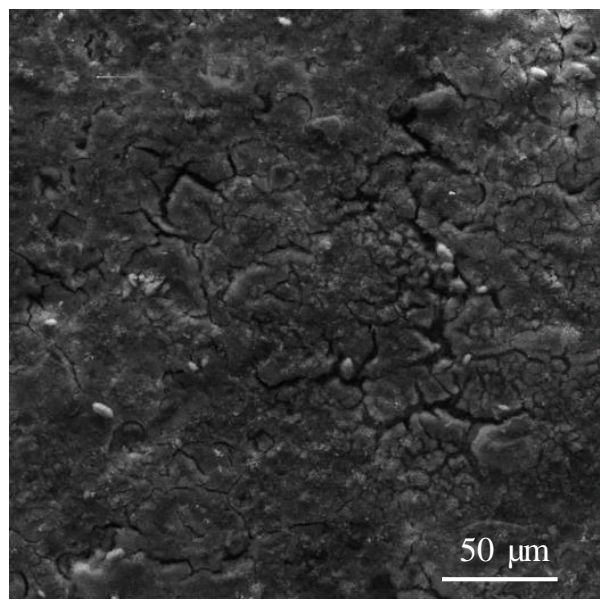

(c)

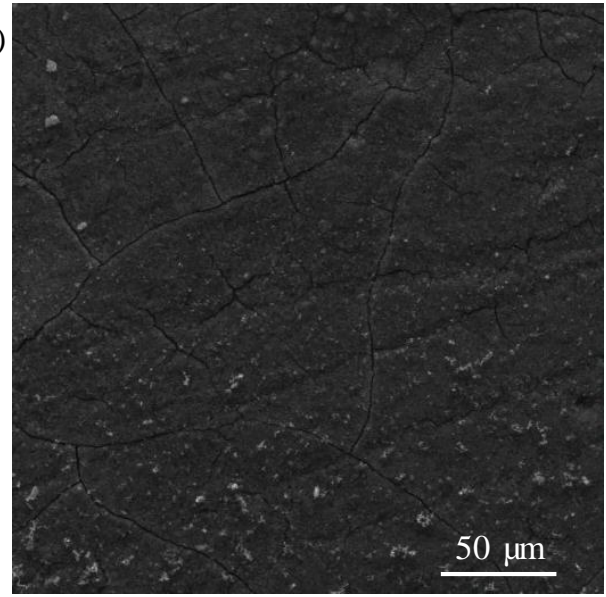

b)

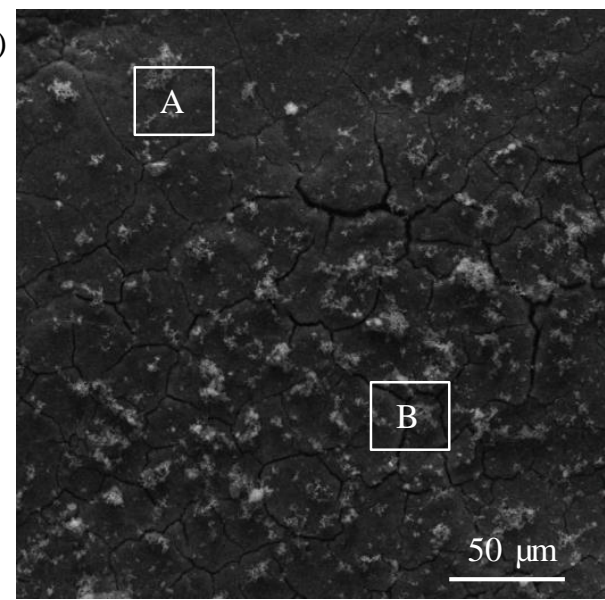

(d)

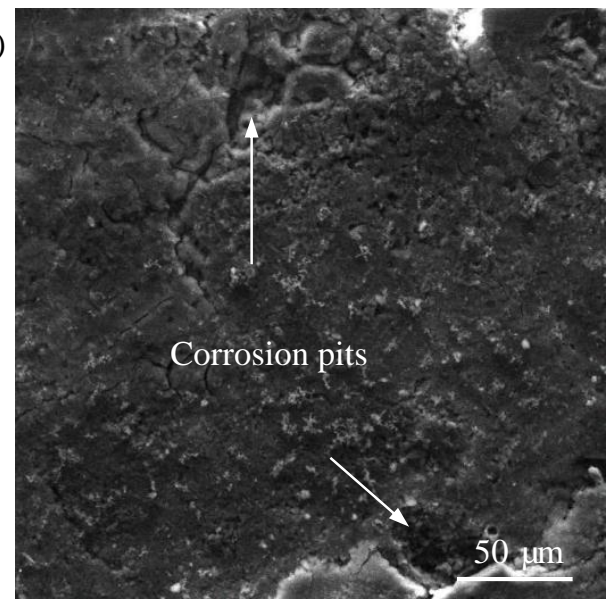

Figure 5. SEM micrographs of rapid laser-melted $\mathrm{Mg}-x \mathrm{Mn}$ alloys after immersion in $\mathrm{SBF}$ at $37^{\circ} \mathrm{C}$ for $48 \mathrm{~h}$ : (a) pure $\mathrm{Mg}$; (b) Mg-1Mn, area A was covered with integrated protective film, while area B presented relatively shallow cracks; (c) $\mathrm{Mg}-2 \mathrm{Mn} ;(\mathbf{d}) \mathrm{Mg}-3 \mathrm{Mn}$.

The hydrogen volume evolution during the soak in SBF was observed, and the results are shown in Figure 6. It indicated that the average hydrogen volume evolution rate from the $\mathrm{Mg}-2 \mathrm{Mn}$ alloy sample $\left(0.017 \mathrm{~mL} \cdot \mathrm{cm}^{-2} \cdot \mathrm{h}^{-1}\right)$ was significant lower than that from the pure $\mathrm{Mg}\left(0.068 \mathrm{~mL} \cdot \mathrm{cm}^{-2} \cdot \mathrm{h}^{-1}\right)$, $\mathrm{Mg}-1 \mathrm{Mn}\left(0.041 \mathrm{~mL} \cdot \mathrm{cm}^{-2} \cdot \mathrm{h}^{-1}\right)$ and $\mathrm{Mg}-3 \mathrm{Mn}$ alloy samples $\left(0.039 \mathrm{~mL} \cdot \mathrm{cm}^{-2} \cdot \mathrm{h}^{-1}\right)$. The enhanced corrosion resistance can partly be ascribed to the increase in corrosion potential caused by the solid solution of $\mathrm{Mn}$, which possessed a higher corrosion potential (-1.18 V) than that of $\mathrm{Mg}(-2.34 \mathrm{~V})$ [16]. As $\mathrm{Mg}$ alloys soak in SBF, the electrochemical reactions occurred as follows:

The reactions were driven by the relative potential difference between the relative anode and cathode. Thus, the increase in corrosion potential of the $\mathrm{Mg}$ matrix, namely, the decrease in relative potential difference, had a beneficial effect on reducing the relative anodic and cathodic reaction kinetics supported by the Mg alloy.

$$
\begin{aligned}
& \text { Anodic : } \mathrm{Mg} \rightarrow \mathrm{Mg}^{2+}+2 \mathrm{e} \\
& \text { Cathodic : } 2 \mathrm{H}^{+}+2 \mathrm{e} \rightarrow \mathrm{H}_{2} \uparrow
\end{aligned}
$$

The reactions were driven by the relative potential difference between the relative anode and cathode. Thus, the increase in corrosion potential of the Mg matrix, namely, the decrease in relative 
potential difference, had a beneficial effect on reducing the relative anodic and cathodic reaction kinetics supported by the $\mathrm{Mg}$ alloy.

On the other hand, the enhancement of corrosion resistance is linked to the grain refinement. Orlov et al.'s study [15] on the effect of microstructure on the corrosion behavior of $\mathrm{Mg}$ alloys revealed that the corrosion resistance of $\mathrm{Mg}$ alloys is closely related to total grain boundary length, and the electrode reaction kinetics supported by the alloy deceased as the total length of the grain boundaries increases. As for the Mg-3Mn alloy, the heterogeneously distributed Mn phase served as a cathode and formed a galvanic couple with the Mg matrix, which accelerated the Mg corrosion rate. As a consequence, the susceptible Mg matrix adjacent to the Mn phase was preferentially corroded and formed some deep corrosion pits (Figure $5 \mathrm{~d}$ ).

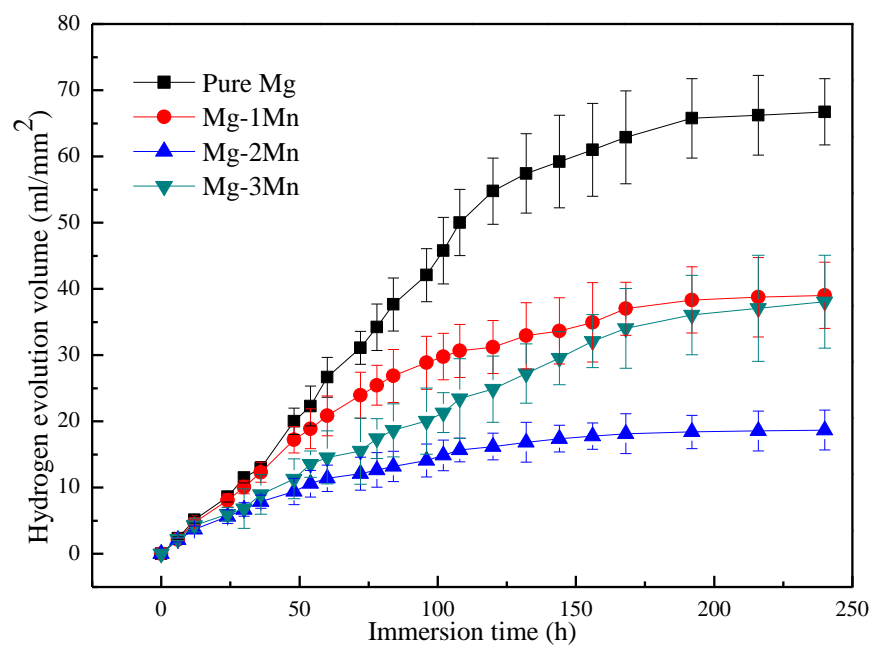

Figure 6. The hydrogen evolution volume of rapid laser-melted $\mathrm{Mg}-\mathrm{x} \mathrm{Mn}$ alloys as function of immersion time.

\section{Materials and Methods}

\subsection{Materials}

The pure Mg powder (99.9\%) with spherical shape (Figure 7a) and the Mn powder (99.9\%) with irregular shape (Figure 7b) were purchased from Shanghai Naiou Nano technology Co., Shanghai, China. Mn powder $(1,2$, and 3 wt \%) were added respectively to the Mg powder, followed by mechanical mixing under a mixed gas atmosphere of $\mathrm{SF}_{6}$ and $\mathrm{CO}_{2}$. Pure $\mathrm{Mg}$ powder was also prepared using as reference sample.
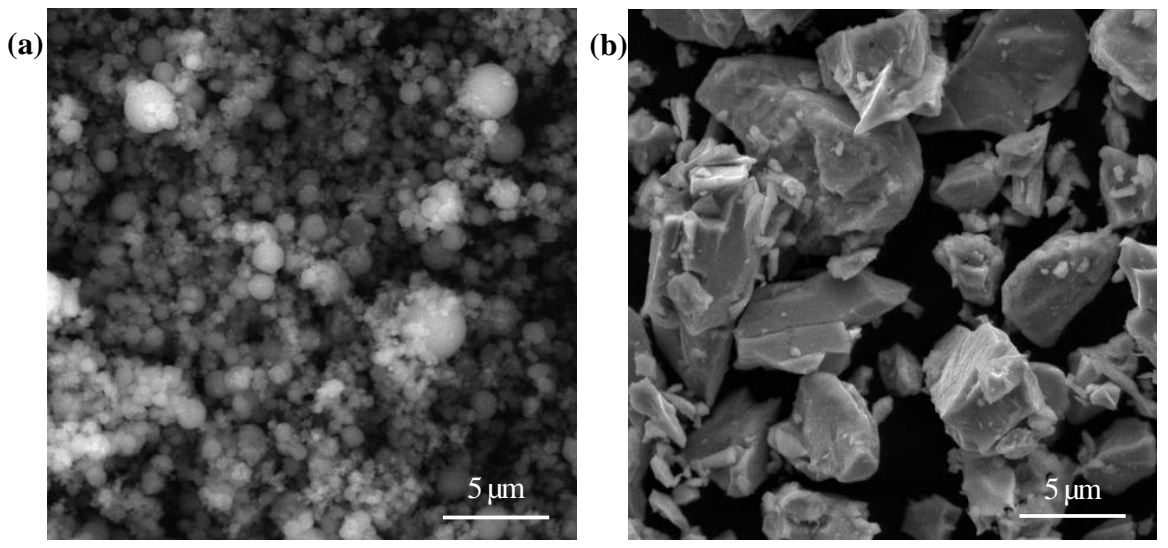

Figure 7. (a) Mg powder and (b) Mn powder. 


\subsection{Laser-Melting Process}

The home-made rapid laser-melting system, as depicted in Figure 8, was composed mainly of a fiber laser with a rated power of $100 \mathrm{~W}$, a powder feeding system, an argon gas protecting system, and a computer control system for process controlling. More detailed information regarding the laser-melting system can be found in [26]. Before the experiments, argon gas was fed into the sealed building chamber to provide an ideal experimental condition. A thin powder layer with a thickness of $100 \mu \mathrm{m}$ was then paved onto the substrate (commercial Mg alloy AZ61) by the powder feeding system. Afterwards, the high energy laser beam scanned the powder layer to form a layer-wise profile according to the CAD data from the computer control system. A simple linear raster scan pattern was used with a scanning length of $4 \mathrm{~mm}$ and a line spacing of $50 \mu \mathrm{m}$. Then, the samples $(4 \mathrm{~mm} \times 4 \mathrm{~mm} \times 2 \mathrm{~mm})$, which had a smooth surface without dimensional distortion, were built up in a layer-by-layer method. The optimized process parameters: laser output power of $70 \mathrm{~W}$, a laser beam scanning speed of $700 \mathrm{~mm} / \mathrm{min}$, and a laser spot diameter of $100 \mu \mathrm{m}$.

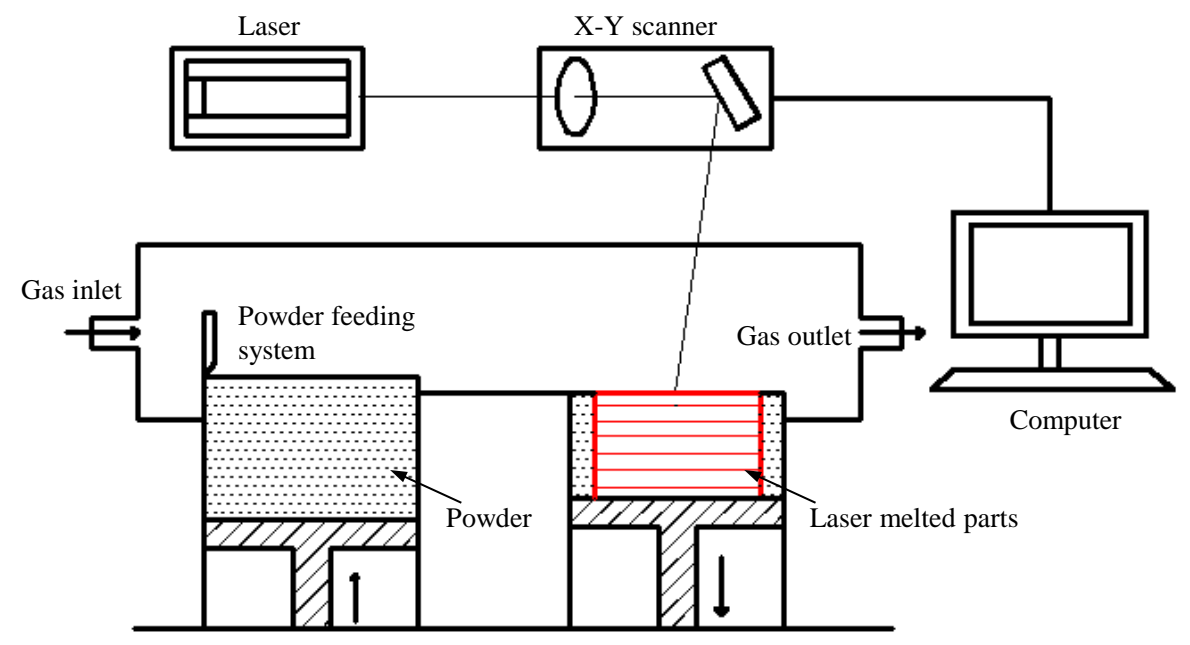

Figure 8. Schematic of laser-melting system.

\subsection{Microstructural Characterizations}

The samples were ground and polished according to standard procedures and etched with a acetic-picral solution ( $10 \mathrm{~mL}$ acetic acid $+4.2 \mathrm{~g}$ picric acid $+70 \mathrm{~mL}$ ethanol) for $10 \mathrm{~s}$. Optical microscopy (PMG3, Olympus Corporation, Tokyo, Japan) observations were performed to analyze the crystalline structure. Moreover, scanning electron microscopy (JSM-5600LV, JEOL Co., Tokyo, Japan) observations in BSE mode and EDS (JSM-5910LV, JEOL Co., Tokyo, Japan) analysis were performed at accelerating voltages of $5 \mathrm{kV}$ and $20 \mathrm{kV}$ to identify the compositional distribution.

Phase analysis was performed by XRD (D8 Advance, Bruker AXS Inc., Karlsruhe, Germany) with the copper target, $\mathrm{K} \alpha \mathrm{X}$-ray $(\lambda=1.54056 \AA)$ at $40 \mathrm{kV}$ and $40 \mathrm{~mA}$. A quick scanning rate of $4^{\circ} \cdot \mathrm{min}^{-1}$ was performed over a wide range of $2 \theta=30^{\circ}-80^{\circ}$ to give an overview of the diffraction peaks. A slower scanning rate of $1^{\circ} \cdot \min ^{-1}$ was then performed over $2 \theta=35.5^{\circ}-37.5^{\circ}$ to obtain a detailed characterization of the diffraction peaks.

\subsection{Mechanical Tests}

The compressive strength of the samples was tested by using a universal testing machine (WD-01, Shanghai Zhuoji instruments Co. Ltd., Shanghai, China) with the maximum load of $100 \mathrm{~N}$ and rate of $0.5 \mathrm{~mm} \cdot \mathrm{min}^{-1}$. Five measurements were carried out for per group. 
The hardness of the samples was tested on the polished surface using a HXD-1000TM/LCD Digital Micro-hardness Tester (Shanghai Taiming Optical Instrument Co., Shanghai, China) under a load of $2.942 \mathrm{~N}$ for $10 \mathrm{~s}$. Five different locations were tested for each sample.

\subsection{Immersion tests}

The immersion tests were performed in SBF according to standard procedures [27]. The temperature was kept at $37^{\circ} \mathrm{C}$ using bath water, and the $\mathrm{pH}$ was adjusted to 7.4. After soaking for $48 \mathrm{~h}$, the samples were removed from SBF, then gently washed with ethyl alcohol, and dried at room temperature. The surface morphologies after soaking were characterized by SEM in secondary electron mode. The hydrogen evolution volume of rapid laser-melted $\mathrm{Mg}-x \mathrm{Mn}$ alloys was monitored during the immersion. Five measurements were carried out for the average.

\section{Conclusions}

The microstructure, mechanical properties, and corrosion resistance of rapid laser-melted $\mathrm{Mg}-x \mathrm{Mn}$ $(x=0-3 \mathrm{wt} \%)$ alloys were investigated. An addition of $2 \mathrm{wt} \% \mathrm{Mn}$ dissolved completely in the $\mathrm{Mg}$ matrix inducing the crystal lattice distortion during the rapid solidification process. Additionally, both mechanical properties and corrosion resistance were enhanced. The $\mathrm{Mg}-2 \mathrm{Mn}$ alloy had an improved compressive strength of $64.2 \mathrm{MPa}$ and a hardness of $56.1 \mathrm{Hv}$, respectively. The enhancement of $\mathrm{Mg}$ corrosion resistance could be attributed to the increase in corrosion potential and grains refinement caused by the solid solution of $\mathrm{Mn}$. It is suggested that rapid laser-melted Mg-2Mn alloy is a potential candidate for future bone implants.

Acknowledgments: This work was supported by the following funds: (1) The Natural Science Foundation of China (51575537, 81572577, 81472058); (2) Overseas, Hong Kong \& Macao Scholars Collaborated Researching Fund of National Natural Science Foundation of China (81428018); (3) the Hunan Provincial Natural Science Foundation of China (14JJ1006); (4) The Open-End Fund for the Valuable and Precision Instruments of Central South University; and (5) The Fundamental Research Funds for the Central Universities of Central South University.

Author Contributions: Youwen Yang, Ping Wu, Qiyuan Wang, Yong Liu and Yuanzhuo Zhou prepared the rapid laser-melted $\mathrm{Mg}-\mathrm{Mn}$ alloy samples and performed the mechanical testing under the supervision of Cijun Shuai and Hong $\mathrm{Wu}$, the microstructural characterization of the alloys under the supervision of Cijun Shuai and Youwen Deng, and the immersion test under the supervision of Cijun Shuai. All authors discussed the results and approved the final manuscript.

Conflicts of Interest: The authors declare no conflict of interest.

\section{References}

1. Chaya, A.; Yoshizawa, S.; Verdelis, K.; Myers, N.; Costello, B.J.; Chou, D.T.; Sfeir, C. In vivo study of magnesium plate and screw degradation and bone fracture healing. Acta Biomater. 2015, 18, 262-269. [CrossRef] [PubMed]

2. Zhang, E.; Yin, D.; Xu, L.; Yang, L.; Yang, K. Microstructure, mechanical and corrosion properties and biocompatibility of Mg-Zn-Mn alloys for biomedical application. Mater. Sci. Eng. C 2009, 29, 987-993. [CrossRef]

3. Kraus, T.; Fischerauer, S.F.; Hänzi, A.C.; Uggowitzer, P.J.; Löffler, J.F.; Weinberg, A.M. Magnesium alloys for temporary implants in osteosynthesis: In vivo studies of their degradation and interaction with bone. Acta Biomater. 2012, 8, 1230-1238. [CrossRef] [PubMed]

4. Yu, K.; Chen, L.; Zhao, J.; Li, S.; Dai, Y.; Huang, Q.; Yu, Z. In vitro corrosion behavior and In vivo biodegradation of biomedical $\beta-\mathrm{Ca}_{3}\left(\mathrm{PO}_{4}\right)_{2} / \mathrm{Mg}-\mathrm{Zn}$ composites. Acta Biomater. 2012, 8, $2845-2855$. [CrossRef] [PubMed]

5. Sun, Y.; Zhang, B.; Wang, Y.; Geng, L.; Jiao, X. Preparation and characterization of a new biomedical Mg-Zn-Ca alloy. Mater. Des. 2012, 34, 58-64. [CrossRef]

6. Hornberger, H.; Virtanen, S.; Boccaccini, A.R. Biomedical coatings on magnesium alloys-A review. Acta Biomater. 2012, 8, 2442-2455. [CrossRef] [PubMed] 
7. Li, Z.; Gu, X.; Lou, S.; Zheng, Y. The development of binary Mg-Ca alloys for use as biodegradable materials within bone. Biomaterials 2008, 29, 1329-1344. [CrossRef] [PubMed]

8. Salahshoor, M.; Guo, Y. Biodegradable orthopedic magnesium-calcium (MgCa) alloys, processing, and corrosion performance. Materials 2012, 5, 135-155. [CrossRef]

9. Gu, X.; Xie, X.; Li, N.; Zheng, Y.; Qin, L. In vitro and In vivo studies on a Mg-Sr binary alloy system developed as a new kind of biodegradable metal. Acta Biomater. 2012, 8, 2360-2374. [CrossRef] [PubMed]

10. Song, G. Control of biodegradation of biocompatable magnesium alloys. Corros. Sci. 2007, 49, $1696-1701$. [CrossRef]

11. Zhang, S.; Zhang, X.; Zhao, C.; Li, J.; Song, Y.; Xie, C.; Bian, Y. Research on an Mg-Zn alloyas a degradable biomaterial. Acta Biomater. 2010, 6, 626-640. [CrossRef] [PubMed]

12. Xie, D.; Zhao, J.; Qi, Y.; Li, Y.; Shen, L.; Xiao, M. Decreasing pores in a laser cladding layer with pulsed current. Chin. Opt. Lett. 2013, 11, 111401.

13. Vilaro, T.; Colin, C.; Bartout, J.D.; Nazé, L.; Sennour, M. Microstructural and mechanical approaches of the selective laser melting process applied to a nickel-base superalloy. Mater. Sci. Eng. A 2012, 534, 446-451. [CrossRef]

14. Nayak, S.; Bhushan, B.; Jayaganthan, R.; Gopinath, P.; Agarwal, R.D.; Lahiri, D. Strengthening of Mg based alloy through grain refinement for orthopaedic application. J. Mech. Behav. Biomed. Mater. 2016, 59, 57-70. [CrossRef] [PubMed]

15. Orlov, D.; Ralston, K.D.; Birbilis, N.; Estrin, Y. Enhanced corrosion resistance of Mg alloy ZK60 after processing by integrated extrusion and equal channel angular pressing. Acta Mater. 2011, 59, 6176-6186. [CrossRef]

16. Makar, G.L.; Kruger, J. Corrosion of magnesium. Int. Mater. Rev. 1993, 38, 138-153. [CrossRef]

17. Leach, R.M.; Muenster, A.M.; Wien, E.M. Studies on the role of manganese in bone formation: II. Effect upon chondroitin sulfate synthesis in chick epiphyseal cartilage. Arch. Biochem. Biophys. 1969, 133, $22-28$. [CrossRef]

18. Liu, Y.; Koltick, D.; Byrne, P.; Wang, H.; Zheng, W.; Nie, L.H. Development of a transportable neutron activation analysis system to quantify manganese in bone in vivo: Feasibility and methodology. Physiol. Meas. 2013, 34, 1593. [CrossRef] [PubMed]

19. Gu, X.; Zheng, Y.; Cheng, Y.; Zhong, S.; Xi, T. In vitro corrosion and biocompatibility of binary magnesium alloys. Biomaterials 2009, 30, 484-498. [CrossRef] [PubMed]

20. Baker, H.; Okamoto, H. ASM Handbook, Volume 3, Alloy Phase Diagrams; ASM International the Materials Information Company: Materials Park, OH, USA, 1992.

21. Asgharzadeh, H.; Yoon, E.Y.; Chae, H.J.; Kim, T.S.; Lee, J.W.; Kim, H.S. Microstructure and mechanical properties of a Mg-Zn-Y alloy produced by a powder metallurgy route. J. Alloys Compd. 2014, 586, S95-S100. [CrossRef]

22. Mora, E.; Garcés, G.; Onorbe, E.; Pérez, P.; Adeva, P. High-strength Mg-Zn-Y alloys produced by powder metallurgy. Scr. Mater. 2009, 60, 776-779. [CrossRef]

23. Zhou, Y.; Wu, G. Analysis Methods in Materials Science-X-ray Diffraction and Electron Microscopy in Materials Science, 2nd ed.; Harbin Institute of Technology Press: Harbin, China, 2007.

24. Ng, C.C.; Savalani, M.M.; Lau, M.L.; Man, H.C. Microstructure and mechanical properties of selective laser melted magnesium. Appl. Surf. Sci. 2011, 257, 7447-7454. [CrossRef]

25. Baril, G.; Pebere, N. The corrosion of pure magnesium in aerated and deaerated sodium sulphate solutions. Corros. Sci. 2001, 43, 471-484. [CrossRef]

26. Shuai, C.; Gao, C.; Nie, Y.; Hu, H.; Qu, H.; Peng, S. Structural design and experimental analysis of a selective laser sintering system with nano-hydroxyapatite powder. J. Biomed. Nanotechnol. 2010, 6, 370-374. [CrossRef] [PubMed]

27. American Society for Testing Materials. Standard Test Methods for Tension Testing of Metallic Materials; ASTM E8-04; ASTM International: West Conshohocken, PA, USA, 2004.

(C) 2016 by the authors; licensee MDPI, Basel, Switzerland. This article is an open access article distributed under the terms and conditions of the Creative Commons by Attribution (CC-BY) license (http://creativecommons.org/licenses/by/4.0/). 